\title{
Thinness as Major Underlying Problem Among Adolescents of Northeast India
}

\author{
Mondal $\mathbf{N}^{1}$
}

\begin{abstract}
Background: Undernutrition is a major public health concern in many of the developing countries of Asia. Due to immense population size, socioeconomic disparities, illiteracy and inadequate access to health facilities prevalence is very high in India. The objective of this study was to determine the prevalence of age-sex specific thinness (low BMI-for-age) among adolescents residing in rural regions in India. Materials and Methods: This cross-sectional study has conducted among 1165 adolescent ( 602 boys; 563 girls) aged 10-18 years of Darjeeling district, West Bengal, India. Anthropometric measurements were height and weight obtained and BMI (weight/height ${ }^{2}, \mathrm{~kg}$ / $\mathrm{m}^{2}$ ) was calculated. The prevalence of thinness was assessed using newly proposed age-sex specific cut-offs of Cole et al. The data were analyzed using chi-square, ANOVA and Least Mean and Square (L,M and S) model approach. Results: Prevalence of overall thinness is $49.10 \%$ ( $51.16 \%$ boys, $46.89 \%$ girls) among rural adolescents. The boys are found to be more sufferer than girls in the different thinness grades include mild (grade I; $27.41 \%$ vs. $27.11 \%$ ), moderate (grade II; $14.62 \%$ vs. $12.08 \%$ ) and severe (grade III; $9.14 \%$ vs. $8.70 \%)(p>0.05)$. The age and sex specific smooth percentile curves of BMI were derived using L,M and $\mathrm{S}$ model approach for further evaluation of nutritional status. Conclusion: The existence of high prevalence of thinness among adolescents indicates nutritional deprivation among rural Indian adolescents. There is an urgent need of appropriate nutritional intervention program to address the public health problem related to undernutrition especially among nutritionally vulnerable segments of adolescents residing in rural regions to ameliorate the nutritional status
\end{abstract}

Key words: Thinness; BMI; undernutrition; Adolescent; India; Anthropometry

\section{Introduction}

$\mathrm{T}_{\mathrm{in}}^{\mathrm{s}}$ he prevalence of undernutrition is a major public health concern in many of the developing countries. The prevalence is very high due to immense population size, socioeconomic disparities, illiteracy and inadequate access to healthcare facilities in India ${ }^{1,2,3,4,5}$. Undernutrition continues to be the principal cause of ill-health condition and premature mortality and morbidity in developing
'Dr. Nitish Mondal, M.Sc., Ph.D., Assistant Professor Department of Anthropology, Assam University: Diphu Campus, Diphu, Karbi Anglong 782 462, Assam, India.

\author{
Address for correspondence \\ Dr. Nitish Mondal, Ph.D \\ Department of Anthropology, \\ Assam University: Diphu Campus, \\ Diphu, Karbi Anglong 782 462, Assam, India. \\ Tel: +91-9613712613 \\ E-mail: nitishanth@gmail.com
}

\section{How to cite}

Mondal N. Thinness as Major Underlying Problem Among Adolescents of Northeast India. J Nepal Paediatr Soc 2014;34(1):39-47.

doi: http://dx.doi.org/10.3126/jnps.v34i1.8922

This work is licensed under a Creative Commons Attribution 3.0 License.

(c) (i)

countries $^{3}$. In India, one of the important aims of nutritional research is to improve the undernutrition status and its related consequences among most nutritionally vulnerable segments especially children, adolescents and women. Furthermore, the foremost objective of nutritional assessment study is to improvement of human health condition ${ }^{6}$. Therefore, the assessments became a priority and bears a potential role in formulating developmental strategies and intervention programme to the nutritionally vulnerable populations in India. The adolescent period is a very 
important phase in the lifespan of an individual. The WHO has been defined by the transition period between childhood to adulthood is referred to as 'adolescence' of 10-19 years aged and characterized by an exceptionally rapid physical growth ${ }^{6}$. Nutritional status of adolescents needs to be monitored closely as they constitutes the next generation of the parenthoods. The nutritional status of the adolescent girls, the future mothers, bear special significance as they contribute significantly to nutritional and health status of the population $2,7,8,9$. Currently, it is estimated that adolescents (aged 10-19 years) contributes to 1.20 billion of the total world population and belonging to the largest population of adolescent cohort of 243 million $(20.00 \%)$ in India ${ }^{2,10}$. Most importantly, a very high proportion of adolescent girls get married at an early age and even before completion of their physical growth $^{7,11}$. Recent national survey report of National Family Health Survey (NFHS-3) has shown that $50.4 \%$ adolescents (aged 15-24 years) are married and among them $39.0 \%$ female either have a child or are currently pregnant $^{2}$.

Anthropometry has become a widely used non-invasive and inexpensive practical technique of assessing nutritional status of individual and/or populations especially in clinical and epidemiological studies $3,4,6,12,13,14,15$. The prevalence of undernutrition is generally assessed by using conventional anthropometric measures of stunting (height-forage), underweight (weight-for-age), wasting (weightfor-height), thinness \{Body Mass Index (BMI)-forage and Triceps skinfold-for-age comparing with international and international standards $s^{3,6,16,17}$. Moreover, these conventional anthropometric indices (e.g., stunting, underweight and wasting) are generally overlapping in nature and markedly underestimate the actual magnitudes of undernutrition prevalence in population ${ }^{3,5,15}$. Furthermore, there are difficulties in the use of different anthropometric cut-offs points to determine the prevalence of underweight/thinness due to between-country comparisons ${ }^{18,19}$. The BMI as measured by weight in kilogram $(\mathrm{kg})$ divided by height in meter square $\left(\mathrm{m}^{2}\right)$ is an anthropometric measure that has been extensively utilized to assess nutritional status \{e.g., chronic energy deficiency (CED) and/or overweight-obesity $\}^{6,16,17}$. The use of $\mathrm{BMI}$ in relation to age (e.g., thinness) was recommended as the best surrogate anthropometric measure of thinness and overweight during adolescents ${ }^{6,16}$. The WHO has already recommended cut-offs are the $<5^{\text {th }}$ and the $>85^{\text {th }}$ percentile of the Nutritional Health and Nutrition Examination Survey (NHANES) references to assess the thinness and overweight respectively ${ }^{6}$. Several studies have already reported the undernutrition among Indian adolescents residing in both rural and urban regions using the WHO recommended references ${ }^{7,8,9,12,14,20,21}$. Very recently, international age-sex specific cutoffs have been proposed to assess thinness ${ }^{16}$ and overweight and obesity ${ }^{17}$ among children and adolescents (aged 2-18 years). The information on the thinness prevalence among adolescents of developing countries like India is needed to be generated due to its immense population size and socio-economic and cultural disparities for the national and international comparisons. The present study has been conducted to assess the prevalence of thinness among adolescents aged 10 to 18 years residing an economically and socially backward rural areas of Darjeeling district, West Bengal, India. Further, to compare the results with available population specific thinness prevalence records to provide more insight into the nutritionally vulnerable populations residing in rural and sub-urban regions of India. However, the recent national study has already advocated that the prevalence of thinness is serious concern among Indian adolescents ${ }^{2}$. Therefore, such assessment of the prevalence will enable the government and non-governmental agencies to formulate policies and initiate developmental strategies for well-being of the nutritionally vulnerable segments of adolescent populations in India.

\section{Materials and Methods}

The present community based cross-sectional study was conducted among 1165 adolescents ( 602 boy and 563 girls) of aged $10-18$ years residing in rural areas of Phansidewa Block (Latitude 26 34' 59" N, Longitude $88^{\circ} 22^{\prime} 0^{\prime \prime}$ E) under Siliguri subdivision of Darjeeling district, West Bengal, India. This community block covers an area of $308.65 \mathrm{~km}^{2}$ and a total population of 1,71,508 individuals (males: 87,945; females: 83,563 ) with a literacy rate of $41.59 \%$ (males: $51.85 \%$; females: $30.80 \%$ ). The region is situated near the IndoBangladesh border region, situated approximately 35-40 km distant from the sub-divisional town of Siliguri. The community block consists of predominant ethnic communities viz., Rajbanshi, Bengalee Muslim population (BMP) and Proto-australoid (e.g., Santal, Munda and Oraon) ethnic populations ${ }^{4}$. There is some government healthcare and supplementation programs in place in the area under study includes Integrated Child Development Service and midday meal facility with primary and junior high schools by Government of India ${ }^{14}$. Initially subjects are identified in the present study are belonging to the major dominant ethnic groups of this region includes Rajbanshi and BMP. The subjects belonging to the adolescent (aged 10-18 years) 
were identified by utilizing stratified random sampling. Age of the subjects was collected using their birth certificates and relevant official records issued by the local government officials. The data were collected from February 2009 to March 2011. The minimum number of subjects required to reliably estimate the prevalence of thinness was calculated utilizing the standard sample size estimation procedures ${ }^{22}$. In this method, the anticipated population proportion of $50 \%$, absolute precision of $5 \%$ and confidence interval of $99 \%$ were taken into consideration. Generally, the prevalence of thinness has been observed $\geq 50 \%$ among children and adolescents in India $8,9,14,23,24$. Hence, the minimum sample size in the present study was estimated to be 661 subjects. A structured schedule was completed by house visits and interviewing the subjects and their parents. The villages of three Gram Panchayets (GP) (the local level government authority) viz., Chathat GP, Phansidewa GP and Jalashnijamtara GP were covered. The socioeconomic status (SES) was evaluated using a modified version of the scale of Kuppuswamy's was proposed by Mishra and Singh ${ }^{25}$. The scale determines the SES based on a score calculated from education, occupation and monthly income. It was subsequently observed that all selected children were belonged to a lower SES group. All the subjects were free from any physical deformities, systematic diseases, nutritional deficiencies and previous histories related to medical and surgical episodes. An informed consent was obtained local village level authorities, subjects and their parents prior to the data collection. The participation of the subject in this study is completely voluntary in nature, and the study was conducted in accordance with the ethical guidelines for human experiments as laid down in the Helsinki Declaration ${ }^{26}$.

\section{Anthropometric measurements obtained}

The anthropometric measurement of height and weight of the subjects was recorded using the standard procedure ${ }^{27}$. Height of the subjects was recorded to the nearest $0.10 \mathrm{~cm}$ with the help of an anthropometer (GPM type, Galaxy Informatics, New Delhi) with the head held in the Frankfort horizontal plane. The weight of the subjects, wearing minimum clothing and with bare feet was taken using a portable weighing scale (Libra ${ }^{\circledR}$, Edryl-India, Tiswadi, Goa) to the nearest $100 \mathrm{gm}$. The $\mathrm{BMI}$ was calculated by using the standard equation: $\mathrm{BMI}=$ weight $(\mathrm{kg}) /$ height $\left(\mathrm{m}^{2}\right)^{6}$. The differences in anthropometric measurements were calculated for testing the co-efficient of reliability $[R=$ $\left\{1-(T E M)^{2} / S^{2}\right\}$, the $S D=$ standard deviation of all measurements] using the technical error measurement $\left\{T E M=V \quad\left(\Sigma D^{2} / 2 N\right), \quad D=\right.$ difference between the measurements, $\mathrm{N}=$ number of individuals measured following the method of Ulijaszek and Kerr ${ }^{28}$. Very high values of $R$ ( $>0.98$ ) were obtained for height and weight using TEM analysis and values were found within the cut-off values ${ }^{28}$.

\section{Assessment of nutritional status (Thinness)}

The prevalence thinness was determined following the newly proposed international age-sex specific BMI reference and cut-off points of Cole et $\mathrm{al}^{16}$. The BMI values were used to determine the definite grades of thinness includes Grade-III (severe), Grade-II (moderate) and Grade-I (mild) ${ }^{16}$. The above classifications are similar to the adult CED classification as proposed by $\mathrm{WHO}^{6}$. This reference population and cut-off points have already been utilized to assess such prevalence among Indian children and adolescents ${ }^{13}$, $29,30,31$.

\section{Statistical analysis}

The data were statistically analyzed using the Statistical Package for Social Sciences (SPSS, Inc., Chicago, IL; version 15.0). The descriptive statistical analysis of the data was depicted in mean and standard deviation. One way analysis of variance (ANOVA) using the Scheffe procedure was done to assess age and sex differences. Chi-square analysis was utilized to assess the differences in prevalence of thinness. A p-value of less than 0.05 was considered to be statistically significant. The Least Mean Square (L, M and S) model approach was utilized to convert the measurements for a child of known age-and sex to evaluate the centile and standard deviation score or z-scores ${ }^{32,33}$. The L, M and $\mathrm{S}$ model approach take into the account the degree of skewness ( $L$ ), central tendency ( $M$; Median) and dispersion or the generalized coefficient of variation (S) for the conversion. This method was used to derive the age-sex specific percentile reference curves of BMI. The centile curves of $3^{\text {rd }}, 10^{\text {th }}, 25^{\text {th }}, 50^{\text {th }}, 75^{\text {th }}, 90^{\text {th }}$ and $97^{\text {th }}$ were derived as reference data. The method summarizes percentiles at each age based on the power of age-specific Box-Cox power transformations used to normalize data. The LMS Chart Maker software program (The Institute of Child Health, London) was used to obtain the smooth centile curves that fitted smooth centile curves to the reference data.

\section{Results}

The age-sex specific subject distribution, descriptive statistics of anthropometric variables and prevalence of different grades of thinness among adolescents are depicted in Table 1 . The age specific 
mean values of weight, height and BMI values were observed to be progressively increased with age among both sexes but an exception was observed among girls in 18 years (in height) and 17 years (in BMI). The overall mean BMI was found to be significantly greater among girls $\left(17.08 \pm 2.57 \mathrm{~kg} / \mathrm{m}^{2}\right)$ than boys $(16.68 \pm 2.69 \mathrm{~kg} /$ $\left.m^{2}\right)(p<0.05)$. The age-sex specific mean BMl values were found higher among girls when compared to boys in most ages, with exception observed in 11 years and 18 years. The age-specific mean $\mathrm{BMI}$ was ranged $14.17 \pm 1.29 \mathrm{~kg} / \mathrm{m}^{2}$ to $19.99 \pm 2.74 \mathrm{~kg} / \mathrm{m}^{2}$ (in boys) and $14.73 \pm 1.70 \mathrm{~kg} / \mathrm{m}^{2}$ to $19.41 \pm 2.20 \mathrm{~kg} / \mathrm{m}^{2}$ (in girls) among 10-18 years. Using ANOVA, statistically significant sexdifferences were observed in height ( $F$ value=30.64; d.f. 1,$1164 ; p<0.01)$, weight ( $F$ value $=5.06$; d.f. 1, $1164 ; p<0.05$ ) and BMI ( $\mathrm{F}$ value=6.53; d.f. 1, 1164; $p<0.05)$. The age-specific differences were also found statistically significant $(p<0.01)$ with height (F-value $=117.20$, d.f. 8, 601), weight (F-value $=144.83$, d.f. 8, 601) and BMI (F-value $=60.95$, d.f. 8,601 ) among boys, and age and height (F-value $=75.46$, d.f. 8, 562), weight (F-value $=99.75$ d.f. 8, 562) and BMI (F-value $=45.26$, d.f. 8,562 ) among girls using ANOVA. The age-and sexspecific smooth percentile curves of $3^{\text {rd }}, 10^{\text {th }}, 25^{\text {th }}, 50^{\text {th }}$, $75^{\text {th }}, 90^{\text {th }}$ and $97^{\text {th }}$ of $\mathrm{BMI}$ were derived for the further evaluation using $L, M$ and $S$ parameter in the model approach statistical procedures are depicted in Figure 1.

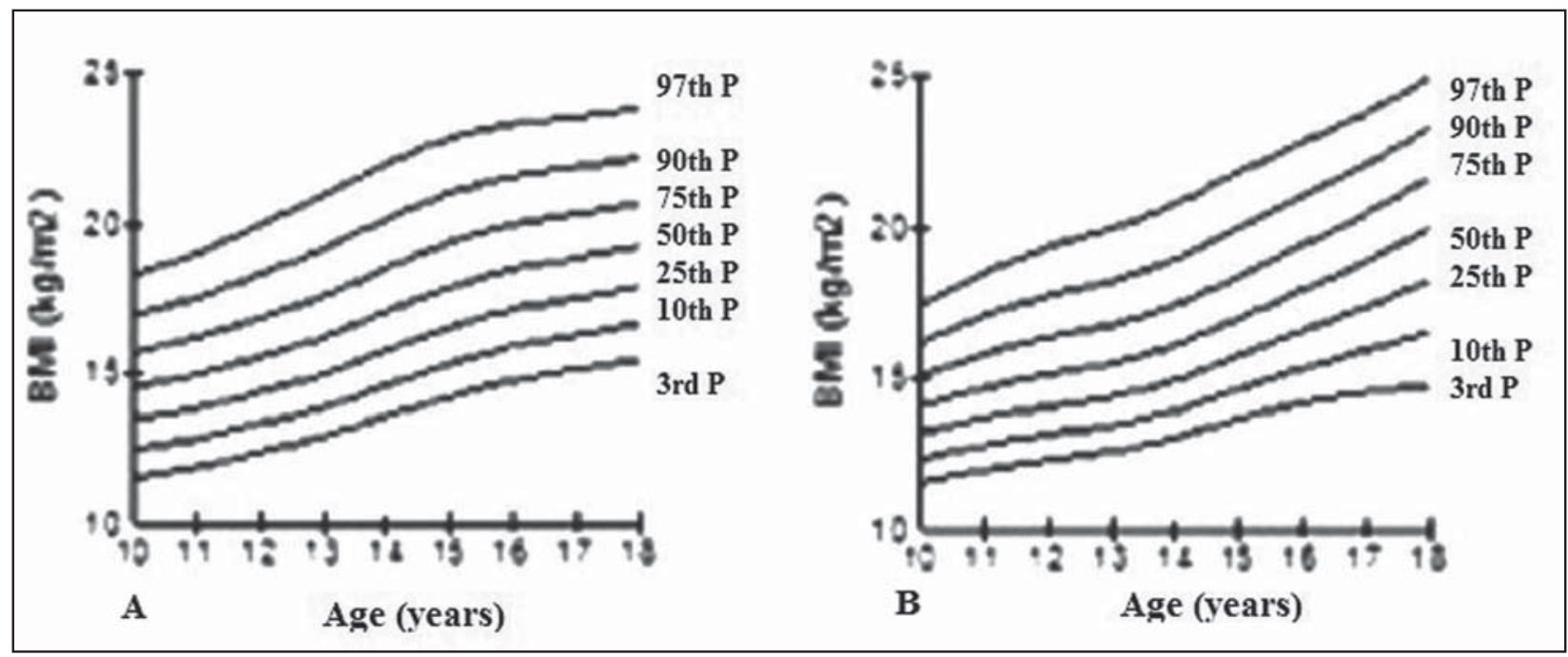

Fig 1: Age and sex specific smooth percentile curves among adolescent boys (A) and girls (B) using L, M and S model approach parameters

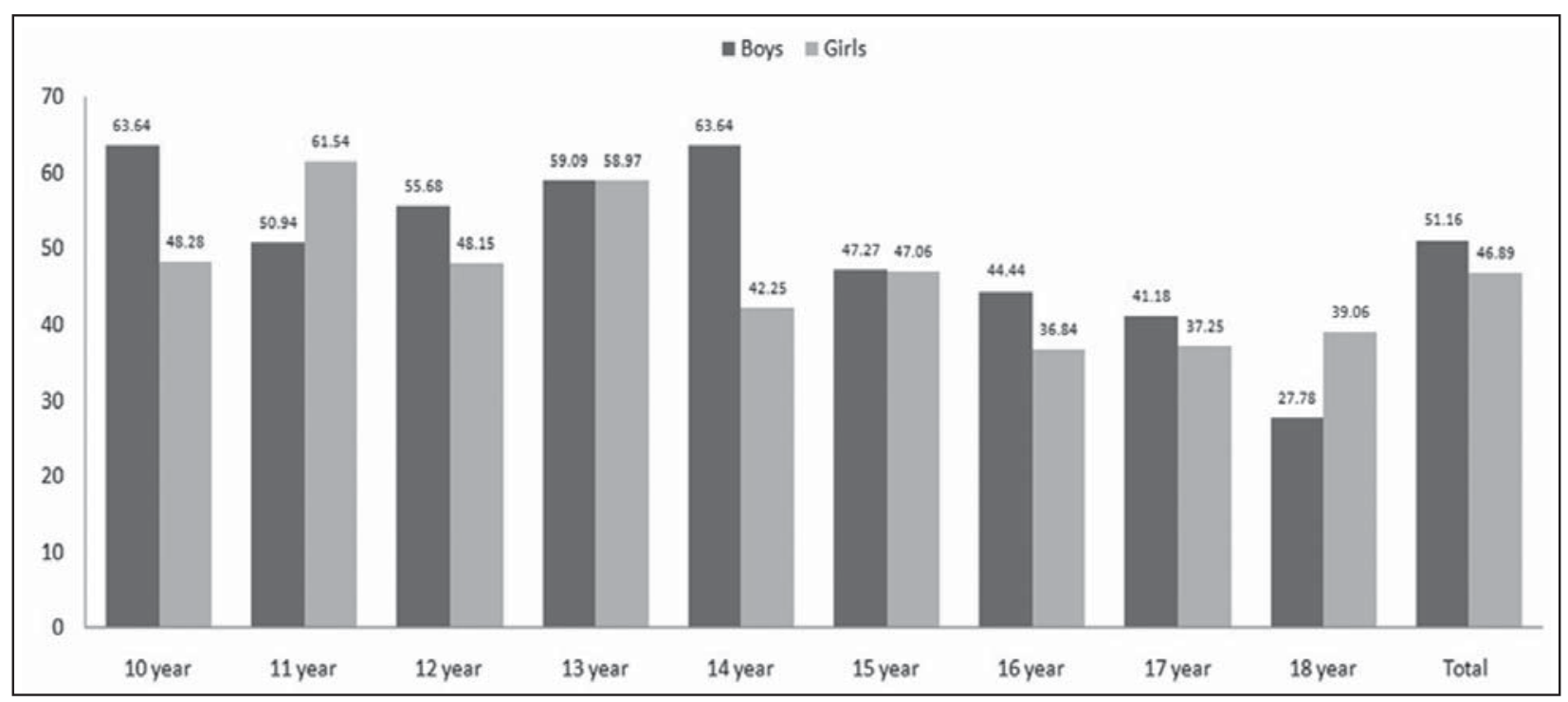

Fig 2: Age- and sex- specific overall prevalence of thinness (low BMI-for-age) among adolescents of Darjeeling, West Bengal 


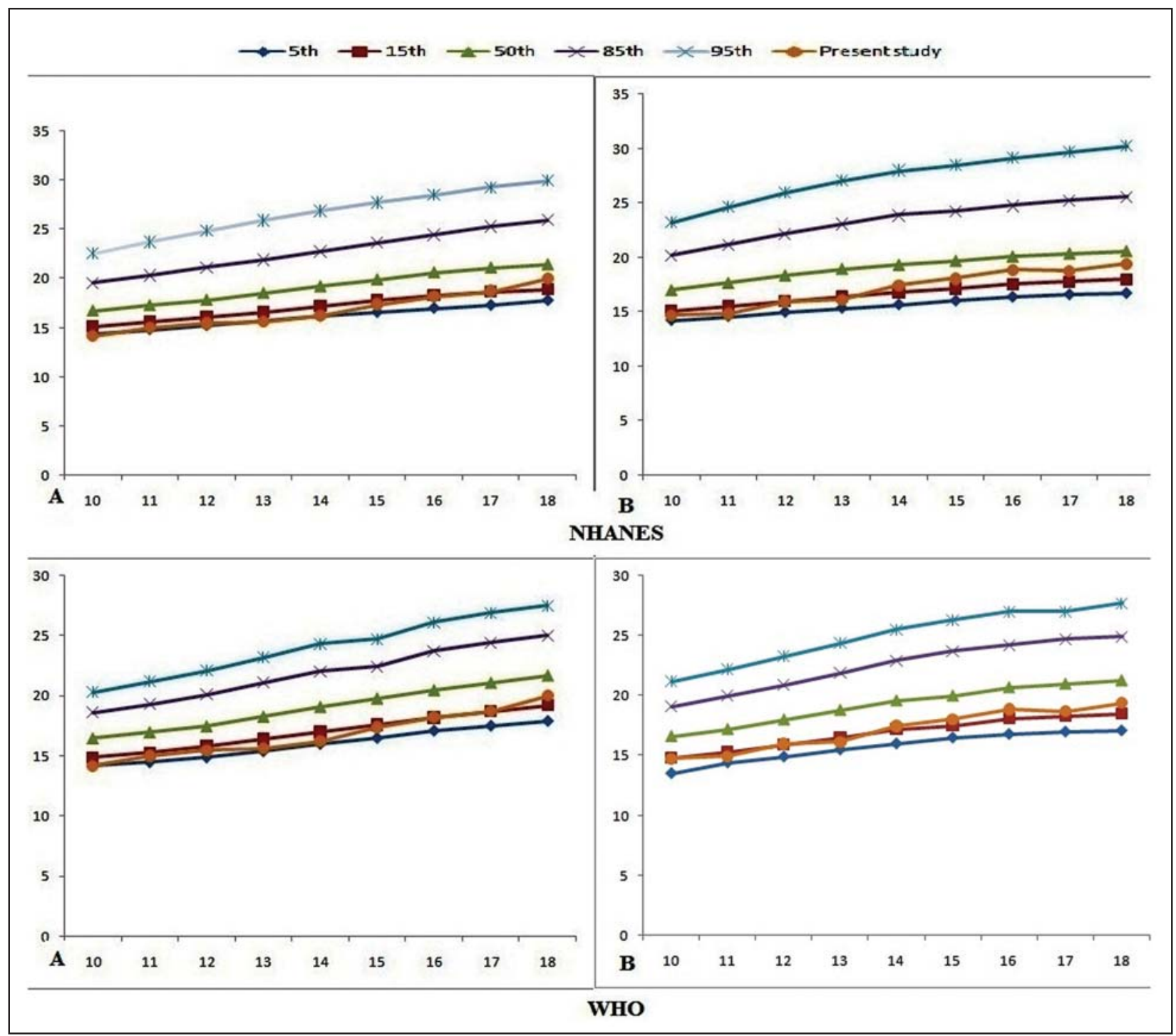

Fig 3: Comparison of age and sex specific mean BMI values of NHANES (WHO, 1995) and WHO (2007) with boys (A) and girls (B)

\section{Prevalence of Thinness (BMI-for-age)}

The overall prevalence of thinness was found to be $49.10 \%$ (51.16\% boys, $46.89 \%$ girls) among rural adolescents $(p>0.05)$. The prevalence of thinness showed that boys were found to be more sufferers in the different thinness grades include mild (grade I; $27.41 \%$ vs. $27.11 \%$ ), moderate (grade II; $14.62 \%$ vs. $12.08 \%$ ) and severe (grade III; $9.14 \%$ vs. $8.70 \%$ ) grades were found greater among boys than girls ( $p>0.05$ ) (Table 1$)$. Age specific trends in thinness prevalence was absent among both sexes but the magnitude is greater among early age groups (10-14 years). Age-specific overall thinness was found greater among 10 years and 14 years old boys (63.64\%) and 11 year old girls (61.54\%), while lower prevalence was observed among 18 years old boys (27.78\%) and 16 years old girls (36.84\%). The prevalence of thinness in different grades was ranged $3.64 \%$ to $36.36 \%$ (in boys) and $4.23 \%$ to $32.69 \%$ (girls). Age-specific prevalence in different grades of thinness ( $p>0.05)$ was found statistically insignificant in both sexes using chi-square analysis ( $p>0.05)$. Ageand sex-specific prevalence of overall thinness among adolescents is also depicted in Figure 2. 
Table 1: Age-sex specific subject distribution, descriptive statistics (mean $\pm S D$ ) and prevalence of thinness among adolescents

\begin{tabular}{|c|c|c|c|c|c|c|c|c|c|c|c|c|c|c|c|c|}
\hline \multirow{3}{*}{$\begin{array}{c}\text { Age } \\
\text { (years) }\end{array}$} & \multirow{2}{*}{\multicolumn{2}{|c|}{$\begin{array}{c}\text { No of } \\
\text { Subjects }\end{array}$}} & \multirow{2}{*}{\multicolumn{2}{|c|}{ Weight (kg) }} & \multirow{2}{*}{\multicolumn{2}{|c|}{ Height $(\mathrm{cm})$}} & \multirow{2}{*}{\multicolumn{2}{|c|}{ BMI $\left(\mathrm{kg} / \mathrm{m}^{2}\right)$}} & \multicolumn{8}{|c|}{ Prevalence of Thinness } \\
\hline & & & & & & & & & \multicolumn{2}{|c|}{ Grade III } & \multicolumn{2}{|c|}{ Grade II } & \multicolumn{2}{|c|}{ Grade I } & \multicolumn{2}{|c|}{ Overall } \\
\hline & Boys & Girls & Boys & Girls & Boys & Girls & Boys & Girls & Boys & Girls & Boys & Girls & Boys & Girls & Boys & Girls \\
\hline \multirow{2}{*}{10} & \multirow{2}{*}{66} & \multirow{2}{*}{5} & 1.85 & 5.31 & 129.60 & 130.92 & 14.17 & 14.73 & \multirow{2}{*}{$\begin{array}{c}6 \\
(9.09) \\
\end{array}$} & \multirow{2}{*}{$\begin{array}{c}5 \\
(8.62)\end{array}$} & \multirow{2}{*}{$\begin{array}{c}14 \\
(21.21)\end{array}$} & \multirow{2}{*}{$\begin{array}{c}6 \\
(10.34)\end{array}$} & \multirow{2}{*}{$\begin{array}{c}22 \\
(33.33)\end{array}$} & \multirow{2}{*}{$\begin{array}{c}17 \\
(29.31)\end{array}$} & \multirow{2}{*}{$\begin{array}{c}42 \\
(63.64)\end{array}$} & \multirow{2}{*}{$\begin{array}{c}28 \\
(48.28)\end{array}$} \\
\hline & & & \pm 3.27 & \pm 4.39 & \pm 6.74 & \pm 9.09 & \pm 1.29 & \pm 1.70 & & & & & & & & \\
\hline \multirow{2}{*}{11} & \multirow{2}{*}{53} & \multirow{2}{*}{52} & & 7.11 & 138.99 & 134.59 & 15.00 & 14.89 & \multirow{2}{*}{$\begin{array}{c}5 \\
(9.43)\end{array}$} & \multirow{2}{*}{$\begin{array}{c}7 \\
(13.46)\end{array}$} & \multirow{2}{*}{$\begin{array}{c}8 \\
(15.09)\end{array}$} & \multirow{2}{*}{$\begin{array}{c}8 \\
(15.38)\end{array}$} & \multirow{2}{*}{$\begin{array}{c}14 \\
(26.42)\end{array}$} & 17 & 27 & 32 \\
\hline & & & \pm 4.89 & \pm 4.65 & \pm 8.32 & \pm 6.79 & \pm 1.88 & \pm 1.69 & & & & & & (32.69) & $(50.94)$ & $(61.54)$ \\
\hline & & & 31.32 & 32.59 & 141.90 & 142.67 & 15.45 & 15.96 & 8 & 8 & 15 & 10 & 26 & 21 & 49 & 39 \\
\hline 12 & 8 & 81 & \pm 5.91 & \pm 5.02 & \pm 8.48 & \pm 6.24 & \pm 1.86 & \pm 1.88 & (9.09) & $(9.87)$ & $(17.05)$ & (12.34) & (29.55) & $(25.93)$ & $(55.68)$ & (48.15 \\
\hline & & & 33.99 & 34.38 & 146.95 & 145.47 & 15.62 & 16.14 & 8 & 12 & 13 & 13 & 18 & 21 & 39 & 46 \\
\hline 13 & 6 & 18 & & \pm 6.55 & 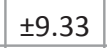 & \pm 7.50 & \pm 1.81 & \pm 2.10 & (12.12) & (15.38) & (19.70) & (16.67) & (27.27) & (26.92) & (59.09) & $(58.97)$ \\
\hline & & & 37.28 & 38.37 & 151.05 & 147.80 & 16.22 & 17.48 & 10 & 3 & 14 & 11 & 32 & 16 & 56 & 30 \\
\hline 14 & & 71 & \pm 6.87 & \pm 6.29 & \pm 9.05 & \pm 6.08 & \pm 1.91 & \pm 2.13 & (11.36) & $(4.23)$ & (15.91) & (15.49) & (36.36) & (22.53) & (63.64) & $(42.2$ \\
\hline 15 & 55 & 51 & 42.29 & 40.05 & 155.67 & 148.78 & 17.37 & 18.05 & 2 & 6 & 11 & 6 & 13 & 12 & 26 & 24 \\
\hline 15 & 5 & & \pm 6.99 & \pm 6.70 & \pm 8.22 & \pm 6.58 & \pm 2.09 & \pm 2.53 & (3.64) & (11.78) & (20.00) & (11.76) & (23.64) & (23.53) & (47.27) & $(47.06)$ \\
\hline & & & 45.44 & 42.64 & 158.05 & 150.25 & 18.19 & 18.87 & 4 & 0 & 8 & 4 & 16 & 17 & 28 & 21 \\
\hline 16 & 63 & & \pm 5.98 & \pm 5.28 & \pm 7.62 & \pm 6.58 & \pm 2.11 & \pm 1.82 & (6.35) & $(0.00)$ & (12.70) & (7.02) & $(25.40)$ & (29.82) & (44.44) & $(36.84)$ \\
\hline & & & 48.70 & 44.37 & 161.29 & 153.84 & 18.71 & 18.74 & 5 & 4 & 2 & 6 & 14 & 9 & 21 & 19 \\
\hline 17 & 5 & 51 & \pm 6.26 & \pm 5.38 & \pm 5.87 & \pm 6.04 & \pm 2.11 & \pm 1.94 & $(9.80)$ & (7.84) & $(3.92)$ & (11.76) & (27.45) & (17.65) & (41.18) & $(37.25)$ \\
\hline & & & 50.95 & 45.08 & 159.53 & 152.59 & 19.99 & 19.41 & 7 & 4 & 3 & 4 & 10 & 17 & 20 & 25 \\
\hline 18 & 12 & 64 & \pm 7.83 & \pm 4.61 & \pm 5.89 & \pm 6.01 & \pm 2.74 & \pm 2.20 & (9.72) & $(6.25)$ & (4.17) & $(6.25)$ & (13.89) & (26.56) & (27.78) & $(39.06)$ \\
\hline & & & 37.77 & 36.49 & 148.88 & 145.21 & 16.68 & 17.08 & 55 & 49 & 88 & 68 & 165 & 147 & 308 & 264 \\
\hline & 602 & $5 t$ & \pm 10.62 & \pm 8.56 & \pm 12.61 & \pm 9.79 & \pm 2.69 & \pm 2.57 & (9.14) & (8.70) & $(14.6)$ & (12.08) & $(27.41)$ & $(27.11)$ & (51.16) & $(46.89)$ \\
\hline
\end{tabular}

Values in parenthesis indicate the percentages

\section{Discussion}

The prevalence of undernutrition among children and adolescent are considered as a serious public health problem in India ${ }^{1,3,4,5,7,8,9}$. It is well known fact that contemporary India consists of a sizable number of ethnic and indigenous elements with enormous amounts of ethnic and genetic diversity ${ }^{34}$. Therefore, the nutritional assessment is necessary for the overall improvement of health situations, nutritional status and thereby development of the population concern and provides an indicator of the well-being of the individuals and/or populations. Therefore, the assessment of nutritional status among children and adolescents belonging to vulnerable segments of the developing countries should be emphasized, not only for the identification the nutritional risks and also to improve health situation. The present study determined the prevalence of thinness using newly proposed reference ${ }^{16}$. This reference was suggested to encourage direct comparison of global trends in thinness prevalence and to provide a classification for public health purposes. Prior to this report, there were no such suitable references for this age group (e.g., 2-18 years) for international comparison except the National Centre for Health Statistics and NHANES ${ }^{6}$. Further, several researchers have already raised their speculation about the suitability of western population based references for the nutritional status assessment among Indian children and adolescents due to large ethnic and/or population physical growth variation ${ }^{8,9}$. Moreover, the newly proposed references ${ }^{16}$ was derived using the multicentre data of the United States, Great Britain, Hong Kong and the Netherlands including data from Brazil (developing country). Several studies have already assessed the prevalence of thinness utilizing this newly proposed reference ${ }^{16}$ among Indian children and adolescents ${ }^{13,29,30,31,35,36,37,38,39}$.

The comparison with the $\mathrm{NHANES}^{6}$ and $\mathrm{WHO}^{40}$ showed that the majority of the adolescents reflecting inappropriate nutritional status and poor physical growth attainments than their normal counterparts (Figure 3). Majority of the boys and girls were found $<15^{\text {th }}$ percentile, while boys among 10 years and 13 years $\left(<5^{\text {th }}\right.$ percentile) and 18 years and girls among 15-18 years were found $>15^{\text {th }}$ percentile of the NHANES ${ }^{7}$. Whereas, comparison with $\mathrm{WHO}^{40}$ reveals that the majority of the subjects was founded $<15^{\text {th }}$ percentile, while exception $\left(<25^{\text {th }}\right.$ percentile) was observed in 14-18 years (in girls) (Figure 3). Several studies have already reported that children and adolescents residing in rural areas were found more nutritionally vulnerable than their urban counterparts. The results reveal that there is a very high prevalence of overall thinness (49.10\%) observed among boys 
(51.16\%) and girls (46.89\%) of Darjeeling, West Bengal, India (Table 1). The adolescents belonging to the early ages (e.g., 10-14 years) found significantly greater thinness prevalence than older ages (e.g., 17-18 years) (Figure 2). A similar trend was already reported among children and adolescents in India. ${ }^{13-14}$ In the present study, the boys were found to be a more sufferer than the girl counterparts $(p>0.05)$. It has also been observed that boys were more sufferer than girls in thinness among tribal and non-tribal children and adolescents residing in rural and sub-urban regions in India $7,13,14,31,35,37,38,39$. The comparison with the present study showed that the prevalence of overall thinness was found lower than the children and adolescents belonging to Bengalee ${ }^{35}$ (62.26\%), rural adolescents of Darjeeling $^{14}$ (63.40\%), Kora-Modi ${ }^{38}$ (67.23\%), Santal ${ }^{37}$ $(56.40 \%)$ and greater than Nepali $^{36}(45.15 \%)$, rural adolescents of Midnapore ${ }^{30}$ (20.80\%) and Sonowal Kachari $^{31}$ (25.99\%). Recent study utilizing data of NFHS-3 showed that a total of $40.20 \%$ (in boys) and $46.80 \%$ (in girls) of the adolescents aged 15-19 years were found sufferer from thinness in India ${ }^{2}$. Such variation in the prevalence of thinness can be attributed due to the large ethnic variation, socioeconomic disparity and diverse socio-cultural and healthcare practices across the populations. However, it is now generally accepted facts that there is a high prevalence of thinness among rural Indian populations with more than $50.00 \%$ of Indian adolescents ${ }^{8,9,14}$.

Several studies have already advocated that the prevalence of undernutrition is better assessed as thinness rather than wasting ${ }^{6,16}$. Available data suggested that the problem of thinness is persistent transversely among different Indian populations with consistent proportions especially among Indian children and adolescents $s^{8,9,31,35,36,37,38,39}$. The undernutrition during childhood and adolescence have not only delayed growth attainment but affected overall the linear mechanism of growth processes 2,20 . The adolescents were suffering from thinness is more likely to develop into thin adults with a lower BMI (e.g., CED) that would have an impact on their reduce physical work productivity as well as lead to greater morbidity and mortality in population ${ }^{6,41}$. These delicate consequences of the adolescence undernutrition were subsequently confirmed by the researchers among different Indian communities ${ }^{1,7,42}$. Moreover, introduction of physical training could substantially improve the work capacity, but inactivity leads to rapid and substantial reductions in the ability to sustain heavy work. Prevalence of thinness is frequently associated with nutritional deficiencies, menstrual irregularity and eating disorders, ${ }^{43,44}$ and adverse reproductive outcomes ${ }^{1,6}$ among adolescent girls and young women. Studies have also confirmed that undernutrition (e.g., CED or thinness) among young women of childbearing age is a risk factor for adverse pregnancy outcomes, such as intrauterine growth-restricted or low-birth weight infants in Indian populations ${ }^{1,45,46}$. Moreover, marriage and early confinement among adolescents are a long established custom in Indian society, with poverty and ignorance magnifying such problems $s^{2,7,11,47}$. The high prevalence undernutrition related to the thinness among adolescents could be the major attribute for such manifestations that indicate to be the thinness is actually being more frequent than overweight-obesity

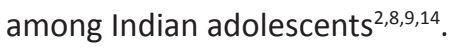

\section{Conclusion}

The adolescent populations of India have a great nutritional risks in term of thinness which is more pronounced among early adolescents. The results of the present study will be useful for policy makers in their endeavour to formulate various developmental, intervention and healthcare programs. Further studies should be conducted using of newly proposed reference population especially to identify the actual proportion of nutritionally vulnerable populations for National and international comparison and to develop of new reference population for future use. Such studies would also help to reveal the enhanced usefulness and effectiveness of the launched and/or ongoing intervention or supplementary programs at targeted populations. There is an urgent need of appropriate nutritional intervention program to address the public health problem related to undernutrition especially in adolescents residing in rural areas to necessary ameliorate the nutritional status.

Acknowledgement: The author gratefully acknowledges the help and co-operation of the Block, Gram Panchayet, local village level authorities and participants during the study. The extended help of Department of Anthropology, North Bengal University is also acknowledged. The financial assistance in the form of UGC-NET-Junior Research Fellowship by the University Grants Commission, Government of India [UGC-Ref. No. 129/(NET-June 2007)] is also acknowledged.

Funding: The financial assistance in the form of UGCNET-Junior Research Fellowship by the University Grants Commission, Government of India [UGC-Ref. No. 129/(NET-June 2007)]

Conflict of Interest: None

Permission from IRB: Yes 


\section{References}

1. Rao S. Nutritional status of the Indian population. J Biosci 2001;26:481-489.

2. Parasuraman S, Kishor S, Singh SK, Vaidehi Y. A Profile of Youth in India. National Family Health Survey (NFHS-3), India, 2005-06. Mumbai: International Institute for Population Sciences; Calverton, Maryland, USA: ICF Macro, 2009.

3. Nandy S, Irving M, Gordon D, Subramanian SV, Smith GD. Poverty, child undernutrition and morbidity: New evidence from India. Bull World Health Organ 2005;83:210-16.

4. Mondal N, Sen J. Prevalence of under-nutrition among children (5-12 years) belonging to three communities residing in a similar habitat in North Bengal, India. Ann Hum Biol 2010;37:199-217.

5. Sen J, Mondal N. Socio-economic and demographic factors affecting the Composite Index of Anthropometric Failure (CIAF). Ann Hum Biol 2012;39:129-36.

6. World Health Organization (WHO). Physical status: the use and interpretation of anthropometry. Technical Report Series No. 854. Geneva: World Health Organization, 1995.

7. VenkaiahK, DamayantiK, NayakMU, Vijayaraghavan K. Diet and nutritional status of rural adolescents in India. Eur J Clin Nutr 2002;56:1119-25.

8. Deshmukh PR, Gupta SS, Bharambe MS, Dongre AR, Maliye C, Kaur S, Garg BS. Nutritional status of adolescents in rural Wardha. Indian J Pediatr 2006;73:139-41.

9. Medhi GK, Hazarika NC, Mahanta J. Nutritional status of adolescents among tea garden workers. Indian J Pediatr 2007;74:343-7.

10. United Nations Children's Fund (UNICEF). The state of the World's children 2011; Adolescence, An Age of Opportunity. New York: UNICEF, 2011.

11. Moore AM, Singh S, Ram U, Remez L, Audam S. Adolescent Marriage and Childbearing in India: Current Situation and Recent Trends. New York: Guttmacher Institute, 2009.

12. Bose K, Bisai S. Prevalence of undernutrition among rural adolescents of West Bengal, India. J Trop Pediatr 2008;54:422-3.

13. Mondal N, Sen J. Thinness is a major underlying problem in Indian children. J Trop Pedtr 2010;56:456-8.

14. Mondal N, Sen J. Prevalence of stunting and thinness among rural adolescents of Darjeeling district, West Bengal, India. Italian J Pub Health 2010;8:54-61.

15. Sen J, Dey S, Mondal N. Conventional nutritional indices and Composite Index of Anthropometric failure: which seems more appropriate for assessing under-nutrition among children? A cross sectional study among school children of the Bengalee Muslim Population of North Bengal, India. Italian J Pub Health 2011;8:66-79.

16. Cole TJ, Flegal KM, Nicholls D, Jackson AA. Body mass index cut offs to define thinness in children and adolescents: international survey. BMJ 2007;335:194.

17. Cole TJ, Bellizzi MC, Flegal KM, Dietz WH. Establishing a standard definition for child overweight and obesity worldwide: international survey. BMJ 2000;320:1240-3.

18. Oner N, Vatansever $U$, Sari A, Ekuklu E, Güzel A, Karasalihoğlu S, Boris NW. Prevalence of underweight, overweight and obesity in Turkish adolescents. Swiss Med Wkly 2004;134:529-33.

19. Kim E, Hwang JY, Woo EK, Kim SS, Jo SA, Jo I. Body mass index cut offs for underweight, overweight, and obesity in South Korean schoolgirls. Obes Res 2005;13:1510e4.

20. de Onis $M$, Dasgupta $P$, Saha, S, Sengupta D, Blossner, M. The National Center for Health Statistics reference and the growth of Indian adolescent boys. Am J Clin Nutr 2001;74:248-53.

21. Rao KM, Laxmaiah A, Venkaiah K, Brahmam GN. Diet and nutritional status of adolescent tribal population in nine states of India. Asia Pac J Clin Nutr 2006;15:64-71.

22. Lwanga SK, Lemeshow S. 1991. Sample size determination in health studies: A Practical Manual. Geneva: World Health Organization.

23. Das S, Bose K. Prevalence of thinness using new international cut-off points among Santal tribal children and adolescents of Purulia District, West Bengal, India. Sri Lanka J Child Health 2011;40:10510.

24. Bisai S, Ghosh T, De GK, Bose K. Very High Prevalence of Thinness among Kora-Mudi Tribal Children of Paschim Medinipur District of West Bengal, India. EJBS 2010;3:43-49.

25. Mishra D, Singh HP. Kuppuswami's socioeconomic status scale - A revision. Indian J Pediatr 2003;70:273-4.

26. Touitou Y, Portaluppi F, Smolensky MH, Rensing L. Ethical principles and standards for the conduct 
of human and animal biological rhythm research. Chronobiol Int 2004;21:161-70.

27. Weiner JS, Lourie JA. Practical human biology. London: Academic Press, 1981.

28. UlijaszekSJ, Kerr DA. Anthropometric measurement error and the assessment of nutritional status. $\mathrm{Br} \mathrm{J}$ Nutr 1999;82:165-77.

29. Biswas S, Bose K, Bisai S, Chakraborty R. Prevalence of Thinness among Rural Bengalee Pre-school Children in Chapra, Nadia District, West Bengal, India. Mal J Nutr 2009;5:155-164.

30. Bisai, S, Khongsdier, R, Bose, K, Mahalanabis, D. Double burden of malnutrition among urban Bengalee adolescent boys in Midnapore, West Bengal, India. Nature Precedings [http://hdl. handle.net/10101/npre.2012.7106.1], 2012.

31. Singh J, Mondal N. Assessment of Nutritional Status: A Case of Tribal Children in Assam, Northeast India. J Nepal Paediatr Soc 2013;33(1):1-7.

32. Cole TJ, Freeman JV, Preece MA. British 1990 growth reference centiles for weight, height, body mass index and head circumference fitted by maximum penalized likelihood. Stat Med 1998;17:407-29.

33. Cole TJ, Green PJ. Smoothing reference centile curves: the LMS method and penalized likelihood. Stat Med 1992;11:1305-19.

34. Indian Genome Variation Consortium. Genetic landscape of the people of India: a canvas for disease gene exploration. J Genet 2008;87:3-20.

35. Chakraborty R, Bose K. Very high prevalence of thinness using new international body mass index cut off points among 5-10 year old school children of Nandigram, West Bengal, India. J Res Med Sci 2009;14:129-33.

36. Das S, Banik SD. Prevalence of thinness among Nepali speaking preschool children of Darjeeling using Body Mass Index cut-off points. Italian J Pub Health 2011;8:241-46.

37. Das S, Bose K. Prevalence of thinness using new international cut-off points among Santal tribal children and adolescents of Purulia District, West Bengal, India. Sri Lanka J Child Health 2011;40:10510.
38. Bisai S, Manna I. Prevalence of Thinness among urban poor pre-School children in West Bengal, India. Sudanese J Public Health 2010;5:193-98.

39. Bisai S, Ghosh T, De GK, Bose K. Very High Prevalence of Thinness among Kora-Mudi Tribal Children of Paschim Medinipur District of West Bengal, India. EJBS 2010;3:43-49.

40. World Health Organization (WHO). WHO child growth standards: head circumference-for-age, arm circumference-forage, triceps skinfold-for-age and subscapular skinfold-for-age: methods and development. Geneva, World Health Organization, 2007, available:http://www.who.int/childgrowth/ standards/second_set/technical_report_2/en/.

41. Strickland SS. Functional consequences of adult malnutrition in developing countries: a review. J Physiol Anthropol 2002;21:1-9.

42. Rao S, Gokhale M, Joshi S, Kanade A. Early life undernutrition and adolescent pregnancy outcome in rural India. Ann Hum Biol 2010;37:47587.

43. Steinhausen HC, Winkler C, Meier M. Eating disorder in adolescence in a Swiss epidemiological study. Int J Eat Disord 1997;22:147-51.

44. Misra M, Aggarwal A, Miller KK, Almazan C, Worley M, Soyka LA, Herzog DB, Klibanski A. Effects of anorexia nervosa on clinical, hematologic, biochemical, and bone density parameters in community-dwelling adolescent girls. Pediatrics 2004;114:1574-83.

45. Bisai S, Mahalanabis D, Sen A, Bose K, Datta N. Maternal early second trimester pregnancy weight in relation to birth outcome among Bengalee Hindus of Kolkata, India. Ann Hum Biol 2007;34:91101.

46. Sen J, Roy A, Mondal N. Association of Maternal Nutritional Status, Body Composition and Socioeconomic Variables with Low Birth Weight in India. J Trop Pedtr 2010;s56:254-9.

47. Banerjee B, Pandey G, Dutt D, Sengupta B, Mondal M \& Deb S. Teenage pregnancy: a socially inflicted health hazard. Indian J Community Med 2009;34:227-31. 